\title{
Late Blight of Potato (Phytophthora infestans) I: Fungicides Application and Associated Challenges
}

\author{
Abdul Majeed ${ }^{*}$, Zahir Muhammad $^{2}$, Zabeeh Ullah $^{3}$, Rafi Ullah ${ }^{3}$, Habib Ahmad $^{4}$ \\ ${ }^{1}$ Department of Botany, Government Degree College Naguman Peshawar, Khyber Pakhtunkhwa, Pakistan \\ ${ }^{2}$ Department of Botany, University of Peshawar, Peshawar, Khyber Pakhtunkhwa, Pakistan \\ ${ }^{3}$ Department of Botany, Hazara University Mansehra, Khyber Pakhtunkhwa, Pakistan \\ ${ }^{4}$ Islamia College University Peshawar, Peshawar, Khyber Pakhtunkhwa, Pakistan
}

A R T I C LE IN F O

Review Article

Received 17 October 2016

Accepted 18 December 2016

Keywords:

Fungicide resistance,

The Great Irish Hunger,

Disease resistance,

Biological control,

Epidemic

*Corresponding Author:

E-mail: majeedpsh@gmail.com

A B S T R A C T

Potato (Solanum tuberosum L.) has been remained an important agricultural crop in resolving global food issues through decades. The crop has experienced enormous growth in terms of production throughout the world in recent decades because of improvement in agricultural mechanization, fertilizers application and irrigation practices. Nevertheless, a significant proportion of this valuable crop is still vulnerable to losses due to prevalence of different viral, bacterial, fungal and nematodes infestations. Late blight, caused by Phytophthora infestans (Mont.) de Bary, is one of the most threatening pathogenic diseases which not only results in direct crop losses but also cause farmers to embrace huge monetary expenses for disease control and preventive measures. The disease is well known for notorious 'Irish Famine' which resulted in drop of Irish population by more than $20 \%$ as result of hunger and potato starvation. Globally, annual losses of crop and money spend on fungicides for late blight control exceeds one trillion US dollars. This paper reviews the significance of late blight of potato and controlling strategies adopted for minimizing yield losses incurred by this disease by the use of synthetic fungicides. Advantages and disadvantages of fungicides application are discussed.

\section{Introduction}

Potato (Solanum tuberosum L.) is an important tuberous crop cultivated for uses as vegetable, food and several other processed products. Basically a temperate crop, potato is best propagated in regions where temperature remains relatively lower $\left(15-30^{\circ} \mathrm{C}\right)$. Generally, potato tubers of small size or cuttings of large tubers possessing eyes are used as propagating organs for cultivation of potato. During 2004 global potato production was recorded as $336 \mathrm{MT}$ which significantly increased to $374 \mathrm{MT}$ (Figure 1), with more than $80 \%$ production recorded in Europe and Asia (Axel et al., 2012; FAOSTAT 2016). China is the major potato growing country followed by India and Russia respectively (Table 1). In Pakistan, total area under cultivation for different crops is roughly 24 million hectare (Mha) of which an average of 1.3 million hectare (Mha) is allocated to potato crop producing $20 \mathrm{MT} / \mathrm{ha}$ (Sajid, 2012; FAOSTAT, 2016). Data presented in Fig. 2 depicts an increase in production of potato as well as area harvested in Pakistan during the period 2004-2014. Growth in production and harvested area for potato cultivation in the country is due to suitable climatic conditions and popularity of crop for domestic consumption. Although, in recent years a steady growth in potato production has been observed, the crop however is still challenged by different climatic adversities and diseases caused by viruses, bacteria, fungi and nematodes.

Late blight of potato is a fungal disease caused by Phytophthora infestans in class Oomycetes which has drastic impacts on growth, yield and overall productivity of potato particularly in moist-temperate conditions (Fry, 2008). Late blight is notoriously known for Irish devastations in the 1840's causing starvation which resulted in death of 1 million people and mass migrations from Ireland to the USA and other European countries (Zadoks, 2008). Although devastations such as the Great Irish Potato Famine are less likely to reoccur because of the profound use of fungicides, late blight of potato, however, is still considered as a threatening and production-limiting disease for potato crop. The pathogen produces asexual propagating structures - sporangia and zoospores - which are dispersed by wind and rain for further infection while sexual reproduction results in yielding oospores which can survive the pathogen for longer periods (Brylinska et al., 2016). The impact of disease is adverse under low temperature $\left(\leq 20^{\circ} \mathrm{C}\right)$ and high humid conditions. Generally, whole plant can be challenged by the pathogen; however, leaves and tubers may be mostly damaged resulting in substantially poor crop yields. Direct crop losses as a result of late blight 
epidemic are difficult to estimate due to lack of monitoring system and coordination between potato growers and agricultural bureaus particularly in developing countries; nonetheless, yearly financial costs (global) are calculated as more than 3.2 billion US\$ (Haverkort et al., 2008) a value which is equivalent to 334.6 billion Pakistani Rupees. Synthesis and marketing of fungicidal compounds has greatly reduced the atrocities of late blight disease in recent years; however, under more humid and cold regions and due to the appearance of resistant strains of the pathogen, fungicides may not prove $100 \%$ effective in controlling disease in addition to their hazardous effects on ecosystem. Thus, in potato growing agro-zones where $P$. infestans predominates with devastating effects, reliance only on fungicides use is not mandatory, rather a holistic approach comprising the timing of sowing and cultivation of resistant cultivars coupled with proper fungicides application needs to be employed. This review paper focuses general aspects of late blight disease, control through fungicides application and associated challenges.

Table 1 Top 5 potato producing countries during 2013-14*

\begin{tabular}{l|c}
\hline \multicolumn{1}{c|}{ Country } & Production (MT) \\
\hline China & 96.01 \\
India & 45.9 \\
Russia & 30.9 \\
Ukraine & 23.0 \\
United States of America & 19.9 \\
\hline
\end{tabular}

*Source: FAOSTAT 2016

\section{Phytophthora Infestans - Propagation, Mode of Infection and Disease Symptoms}

$P$. infestans is a diploid, mycelial plant pathogen that fits better in Kingdom Fungi because of many common features the pathogen shares with fungal relatives. The pathogen has branched mycelium which bear lemon shaped sporangia. These sporangia serve as asexual propagating organs which on detachment from parent mycelium are disseminated by wind, rain water and mechanical means to produce new mycelia of the pathogen on host tissues. Lemon shaped sporangia germinate directly by producing germ tube when temperature is above $20^{\circ} \mathrm{C}$ and conditions are dry but produce tiny structures 'zoospores' in the presence of moisture and low temperature ranging between 10 and $15^{\circ} \mathrm{C}$ (Fry, 2008). Germination either from sporangia (in dry and high temperature) or from zoospores (in humid and low temperature) results in the successful establishment of new hyphae of $P$. infestans in host tissues when growth conditions are suitable for pathogen. This asexual cycle may recur many times subject to the presence of host and ideal environment. Sporangia and zoospores cannot maintain their lives in soil, air or water for long time if host is not available.

Besides asexual reproduction, the presence of matable hyphae (A1 \& A2) may contribute to sexual union resulting in the formation of antheridia and oogonia which are brought together by hormonal signals resulting in oospore production (Chern et al., 1996; Fry, 2008). Generally, temperature and humidity apparently have no role in facilitation of sexual reproduction except that asexual reproduction may proceed more rapidly under cool and moist conditions than sexual reproduction do. Like sporangia and zoospores, oospores are also capable of producing new mycelia via germ tube and thereby multiplying the pathogen. Oospores have advantages over sporangia and zoospores of being resistant to dryness and higher temperature and can maintain their survival in soil up to four years (Yuen and Andersson, 2013). Thus, $P$. infestans is capable of survival and infection in on-going cropping season by producing sporangia and zoospores through asexual reproduction while for the next season(s) by sexually formed oospores. Either source of inoculum wither sporangia, zoospores or oospores harbored in leaves, tubers, debris and in soil can infect fresh plants when they come into contact. Entry into the host is usually via stomata of leaves and stems by germ tube of sporangia, zoospores or oospore; however, peel of tuber or injured parts may also provide attractive side for infection.

Once the host tissues are challenged by the pathogen its mycelium starts proliferation. Specialized rounded structures haustoria are formed which establish intercellular connection with host tissues by disrupting host cell wall for nutrient absorption (Whisson et al., 2016). Profuse intercellular growth of mycelium and haustorial development result in cell damage of host with the appearance of greenish brown or yellowish spots which turn black with disease progress (Fig. 3). When climate is suitable for growth of $P$. infestans, other parts of potato are severely damaged resulting in wilting of whole plants (Fig 4). Under moist conditions, sporangia formation on sporangiophores occurs which commence sporulation, making the mycelia visible at lower surface of leaves (Schumann and D'Arcy, 2000). The sporangia are then disseminated over long distance by air from sites of infection to healthy potatoes and tomatoes. Sporangial germination occurs either directly by protruding germ tube or by producing motile zoospores within hours in the presence of moisture when they come into contact with host's leaves which will initiate disease symptoms in two or three days (Fry, 1998). Successful infection and establishment of late blight disease is a complex process which involves interaction between host and the pathogen under influential roles of environment. This interaction is influenced by several factors such as availability of moisture, prevailing temperature, virulence capacity of the pathogen and degree of resistance of host plants. In ideal growth conditions for pathogen, greater disease damage is caused resulting in greater crop losses.

\section{Control Methods}

One of the most important and reliable techniques used for late blight control is the application of chemical substances termed as fungicides (Majeed et al., 2014a). Fungicides are different formulations of inorganic and organic materials which have the potentials of growth 
inhibition, killing of zoosporangia/zoospores and mycelium of the causative organism. Application of fungicides at suitable time and intervals during potato growing period helps potato growers to manage potential crop damage. Besides fungicides applications, cultivation of late blight (LB) resistant cultivars is an appealing approach to resist late blight outbreak. However, to date no cultivar of potato elsewhere has sufficient resistance level to $P$. infestans (Song et al., 2003). Elevation of secondary metabolites particularly glycoalkaloids and phytoalexins in leaves and tubers of potato via breeding may offer host defense against LB pathogen to some degree, however, these practices will not completely neutralize the adverse effects of late blight (Majeed et al., $2014 b, c)$. Use of plant extracts and natural products as alternative measures to fungicides application are likely to achieve sustainable control of LB posing less severe challenges to environment and minimizing the risks associated with emerging fungicide-resistant strains of $P$. infestans (Majeed et al., 2011, 2015). Thus, there is a great need for search of integrated and eco-friendly methods for control of $P$. infestans.

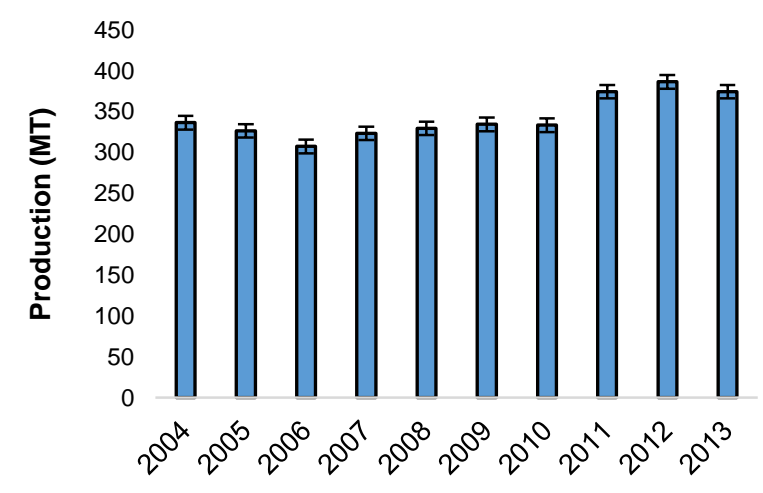

Figure 1 Global potato production during 2004-2013 (Source: FAOSTAT 2016)

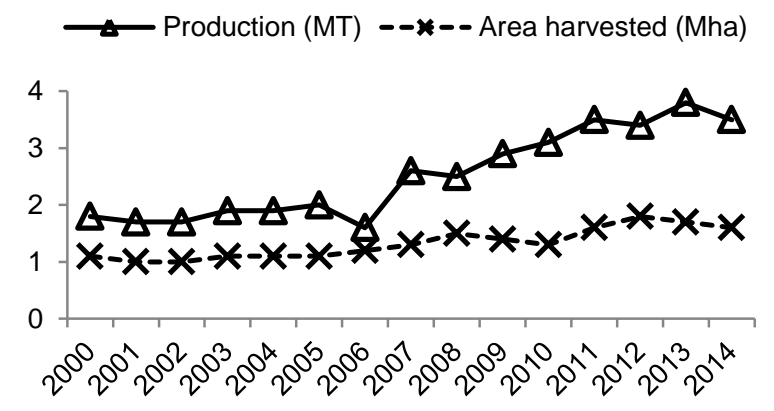

Figure 2 Potato production and area harvested in Pakistan during 2004-14 (Source: FAOSTAT 2016)

\section{Late Blight Fungicides - Advantages and Disadvantages}

\section{Nature and Mode of Activity}

Fungicides are chemical substances of diverse origin which are toxic to target fungal pathogens. They may be formulated from inorganic or organic ingredients or combination of both. Fungicides are capable of destroying pathogenic fungi by killing their mycelia, zoosporangia, zoospores or other propagating structures. Mechanism of suppressive effects of different fungicides is different. Possible explanation of mode of activity of commonly used fungicides may include their capacity to disrupt cell membranes of target parasite, activate catalytic enzymes of the host tissues to suppress the growth of the pathogen and making its growth conditions unsuitable by pathotoxic activity. Fungicides may prevent zoospore encystment, may cause their bursting and prevent the protoplast of Oomycete pathogen to regenerate (Cohen et al., 2007). There are several different classes of fungicides used for LB control. Late blight may be effectively controlled when application of fungicides is made before infection because most fungicides have protective effects and they lose efficacy after $P$. infestans once establish itself in plant tissues (Schwinn and Margot, 1991). In general, there are two types of fungicides available to potato growers to handle LB diseaseprotectant and systemic. Many of the LB fungicides have protective properties i.e., they tend to protect host plant by inhibiting or killing the propagating structures of LB pathogen before it establishes itself. Sprays of protectant fungicides on potato foliage are generally done 4 weeks after planting with further successive application made at 7-10 day intervals. However, in wet and cool conditions 5-7 day intervals of spraying reveals good results.

Protectant fungicides do not persist for long duration because wind and rain can wash down their effective ingredients (Deahl et al., 1993; Miller et al., 1998). Fungicides are effective against the disease if they are applied in wet conditions and with a greater frequency rate (Schepers, 1996), however, under wet conditions and heavy rainfalls, they may show less effectivity because of rain erosion and difficulty in spraying (Kankwatsa et al., 2003). On the other hand, systemic fungicides are more persistent as compared to protectant fungicides and may be used to control the late blight disease. Systemic fungicides can reach deeper parts of the host plant and they remain active longer. Applications of systemic fungicides are made beginning 60 days after planting with up to 3 applications at 10-day intervals (Deahl et al., 1993; Mukalazi et al., 2001; Mantecon, 2007). In addition to contact and systemic fungicides, local and acropetal penetrants are also used which for some protective barriers on and with penetration to host tissues (Jung et al., 2007).

\section{Change in Sensitivity of P. Infestans to Metalaxyl Fungicides}

It has been observed during the last few years that new strains of $P$. infestans has been reported which show insensitivity to metalaxyl containing fungicides (Gisi and Cohen, 1996; Inglis et al., 1996). Although, metalaxyl containing fungicides reveals good results against $P$. infestans (Gisi and Cohen, 1996) continuous applications of these fungicides has resulted in resistance development in P. infestans (Clayton and Shattock, 1995; Colon et al., 1995; Delen, 2016) and a considerable proportion of metalaxyl-insensitive genotypes of $P$. infestans has been 
documented from different regions worldwide. In 1980, phenylamide resistant isolates of $P$. infestans were detected on field-grown potatoes in Ireland, Netherlands and Switzerland and the detection of these resistant isolates were associated with a decline in the disease control (Jmour and Hamada, 2006). Since then various workers have investigated the occurrence of resistant isolates of $P$. infestans from different potato growing regions. Besides phenylamides, other classes of fungicides which exhibited good suppressive effects against oomycete pathogen have also lost their effectivity after 1980s. Goodwin et al. (1996) confirmed that isolates of $P$. infestans originated from 13 out of 15 states US, Columbia and Canada were resistant to Phenyl amide class. Gisi and Cohen (1996) have established larger samples of collected isolates were insensitive to fungicides especially meatalxyl compounds. Kato et al. (1997) on the other hand argue that emergence of virulent strain could not be explained on the basis of insensitivity of isolates to fungicides as they observed that 4 clonal lineages commonly found in US and Canada did not show resistance to protectant chlorothalonil fungicides and mancozeb. Saville et al. (2015) has recently shown that clonal lineages of $P$. infestans (US11 and US8) were insensitive to applied fungicides such as cymoxanil, mandiprompamid, mefenoxam etc.

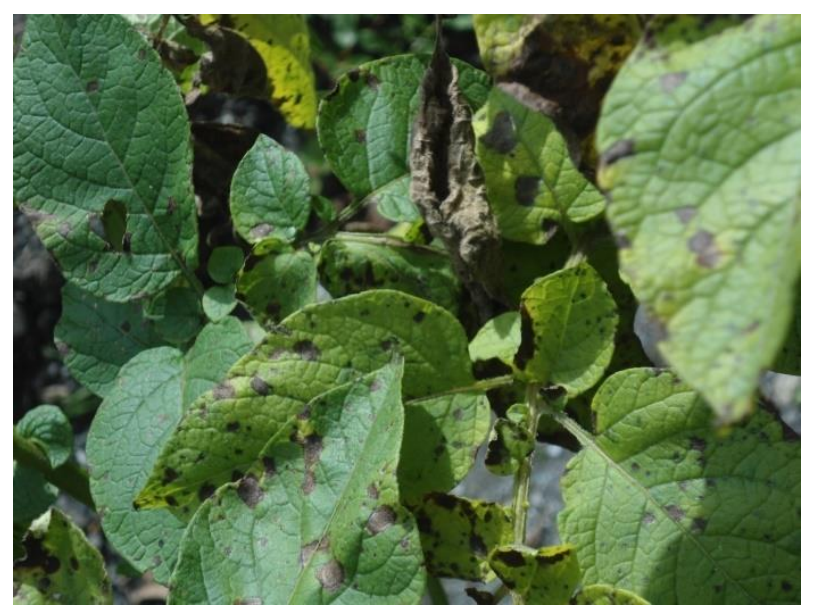

Figure 3 Symptoms of late blight disease on potato foliage

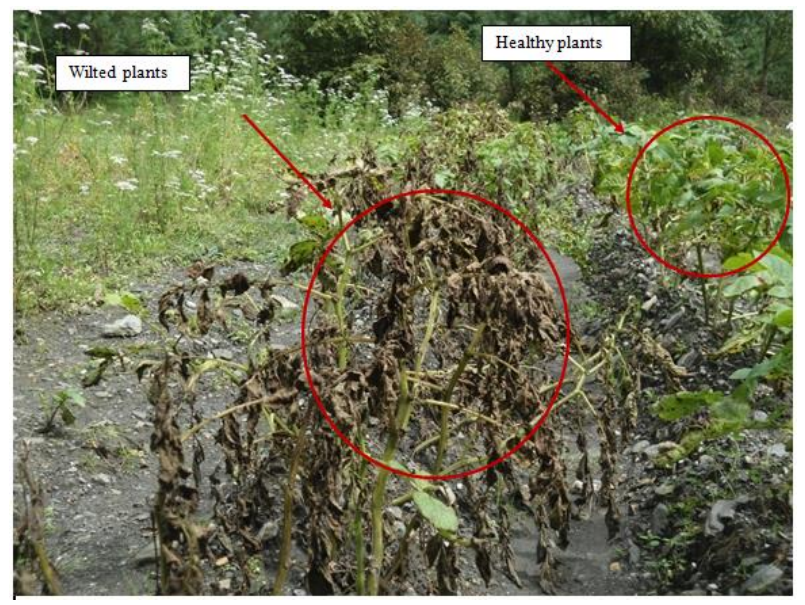

Figure 4 Completely wilted plants due to late blight damage

\section{Reasons for Resistance Development}

After the 1845 s late blight epidemics in Ireland and Europe, $P$. infestans had grabbed sufficient attention of plant pathologists to deal with potential enemy. Several researches were focused on finding cure of the disease. Resultantly, different synthetic chemicals were formulated for suppressing late blight pathogen. Until 1980s, almost all types of fungicides prepared for late blight control were effective and the primary methods to cope with $P$. infestans. The appearance of different genotypes during the 1980s opened a new chapter in plant pathology highlighting "resistance and insensitivity" of the newly emerged genotypes to "phenylamide" and "metalaxyl" fungicides. Several studies document those different fungicides once highly effective in suppressing $P$. infestans before the 1980 s have now lost their efficacy of controlling late blight in different parts of the world (Goodwin et al., 1998; Yuan et al., 2006). Vincelli and Dixon (2002) argues that there are two types of resistance development -qualitative and quantitative- in pathogen towards fungicides. In quantitative resistance, new variants show comparatively less sensitivity to fungicides than their parental types. This type of resistance can be overcome by increasing the dose and spray frequency of fungicides. On the other hand in qualitative resistance, progenies show greater resistance to fungicides than their parents and cannot be compromised by increasing dose rate and frequency of fungicide spray (Vincelli and Dixon, 2002). Reports of increased number of isolates and cases of resistance development to fungicides are generally assigned to the appearance of new genotypes. First possible reason of the appearance of resistant variants is successive application of the particular fungicides. Continuous application of the particular fungicides results in segregation and recombination of genes with potential resistance to applied fungicides in the progenies of $P$. infestans; thus in a particular pathosystem new variants of $P$. infestans are likely to emerge in response to frequent usage of a fungicide. Secondly, migration of diverse strains of $P$. infestans to and from different agro-ecological systems is likely an important factor in resistance development to fungicides. Since mixed occurrence of diverse genotypes in a given agricultural ecosystem arised from migration, nutation, genetic recombination or evolution does not imply that all the genotypes of $P$. infestans will show similar responses to the applied fungicides in that agro-ecosystem; thus there are chances of emergence of new strains with fungicide resistance (Majeed et al., 2015). These strains may dominate the particular agro-system by eliminating fungicides-sensitive strains. Selection pressure as a result of continuous application of fungicides will presumably increase the frequency of resistant genotypes in a population (Grunwald et al., 2006). Kato et al. (1997) give four reasons of the appearance of new variants and replacement of old population of $P$. infestans by the new variants: 1, migration; 2 , enhanced pathogenicity of $P$. infestans strains to tomato; 3 , enhanced pathogenic fitness of $P$. infestans strains on potato and; 4 , loss of efficacy of the protectant fungicides in that environment. Moreover, 
sexual reproduction among $\mathrm{A} 1$ and $\mathrm{A} 2$ genotypes produces oospores which can overwinter cool temperatures and will definitely yield progenies possessing variable traits. Thus genetic recombination may possibly contribute to the emergence of resistant pathotypes. Role of mutation in developing fungicides resistance cannot be excluded as well. Mutation may occur in parental strains as a result of UV radiation in potato fields located at high altitudes or due to some of the fungicides containing mutagenic chemicals. These mutant strains have possible opportunity to give rise to resistant strains directly. Natural mutations in the course of gamete formation and then giving rise to resistant progenies are equally important contributing factors for evolution of fungicides resistance in isolates of $P$. infestans. Additionally, use of site-specific fungicides pose a high risk of development resistance in target pathogen compared to multi-site fungicides which act at different sites of host tissues affecting not only the target pathogen but also inhibit the growth of other microbes (Gisi and Sierotzki, 2008).

\section{How Resistance is Overcome}

In order to manage fungicides resistance development in $P$. infestans and several other phyto-pathogens, causes of resistance induction clearly need to be understood. Understanding the reasons of resistance development can be achieved by surveys, sensitivity tests of isolates, mitochondrial haplotyping, using molecular and genetic approaches. In agro ecosystems where enhanced pathogenicity towards tomato is dominant, mixed cultivation of potato and tomato may offer a way to reduce high risks of fungicides resistance incidence. Frequent uses of fungicides need to be avoided. Some alternative measures in this regards can help in reducing the fungicides frequencies. For instance, use of cultivars with late blight resistance can be useful in reducing reliance on fungicides application. If the use of fungicides is unavoidable such as in favorable conditions for $P$. infestans' growth and spread, then instead of using a specific fungicide application, combination of different classes of fungicides may be useful in management of fungicides resistance risks. Similarly, spray of multi-site fungicides are considered as low contributing factor in resistance development than site specific fungicides (Gisi and Sierotzki, 2008). Reducing the spray frequencies and enhancing the spray intervals, alternative application of different group of fungicides in a growing season can manage the risk (Vincelli and Dixon, 2002). Up gradation of existing fungicides or formulation of new ones on the basis of resistance risk surveys generally are helpful tactics to overcome the resistance development risks for some years.

\section{Summary}

Late blight of potato caused by $P$. infestans is primarily managed in most of the agro systems by continuous usage of fungicides. Although fungicides application results in reducing crop damages and economic losses; however, their use have given rise to appearance of resistance induction in $P$. infestans strains which make late blight control difficult for potato growers. Currently, in several agro-ecosystems, resistant pathotype dominate than the wild ancestors. This dominance of fungicides resistant strains is partly because of successive application of fungicides and partly due to migration, genetic recombination, mutation events, evolution and high selection pressure. The emergence of new variants of $P$. infestans continuously poses high risk of fungicides resistance. To manage risk of fungicides resistance development in the isolates of $P$. infestans, sustainable approaches are dire required. First, extensive surveys and risk assessment are extensively necessary in different geographic locations to indicate prevalence of isolates of $P$. infestans which are resistant to certain classes of fungicides. On the basis of surveys and risk assessments, corresponding measures may be taken. Secondly, since continuous use of fungicides may result in high selection pressure and subsequent dominance of resistant strains in a given environment, therefore, spray frequencies need to be reduced and their interval of application be increased. Thirdly, using different fungicides in mixtures instead of solo use seem to be helpful in reducing resistance development risks. Finally, mixed cultivation of potato, tomato and other hosts of $P$. infestans in a specific agro eco-climate are likely to manage fungicides resistance induction in strains of $P$. infestans.

\section{References}

Axel C, Zannini E, Coffey A, Guo J, Waters DM, Arendt EK. 2012. Ecofriendly control of potato late blight causative agent and the potential role of lactic acid bacteria: a review. App. Microbiol. Biotechnol., 96(1): 37-48.

Brylinska M, Sobkowiak S, Stefanczyk E, Sliwka J. 2016. Potato cultivation system affects population structure of Phytophthora infestans. Fungal Ecol., 20: 132-143.

Chern LL, Ko WH, Tang CS. 1996. Factors affecting yields of alpha hormones of Phytophthora parasitica obtained by adsorption. Can. J. Microbiol., 42: 172-176.

Clayton RC, Shattock RC. 1995. Reduced fungicide inputs to control Phytophthora infestans in potato cultivars with high levels of polygenic resistance. Potato Res., 38(4): 399-405.

Cohen Y, Rubin E, Hadad T, Gotlieb D, Sierotzki H, Gisi U. 2007. Sensitivity of Phytophthora infestans to mandi propamid and the effect of enforced selection pressure in the field. Plant Pathol., 56: 836-842. doi: 10.1111/j.1365-3059.2007.01625.x

Cohen Y. 1996. U.S. Patent No. 5,494,684. Washington, DC: U.S. Patent and Trademark Office.

Colon LT, Turkensteen LJ, Prummel W, Budding DJ, Hoogendoorn J. 1995. Durable resistance to late blight (Phytophthora infestans) in old potato cultivars. European J. Plant Pathol., 101(4): 387-397.

Deahl KL, Inglis DA, DeMuth SP. 1993. Testing for resistance to metalaxyl in Phytophthora infestans isolates from northwestern Washington. American Potato J., 70(11): 779-795.

Delen, N. 2016. Fungicides. Turkiye, Nobel Press, ISBN no:978605-320-347-6.

FAOSTAT. 2016. Food and Agricultural Organization Statistical database, Crop production. http://faostat3.fao.org/download/ Q/QC/E (accessed on 1st January 2016)

Fry WE. 1998. Late blight of potatoes and tomatoes. Department of Plant Pathology, NYS College of Agriculture and Life Sciences, Cornell University, Ithaca, NY 
Fry WE. 2008. Phytophthora infestans, the plant (and R gene) destroyer. Mol. Plant Pathol., 9: 385-402.

Gisi U, Cohen Y. 1996. Resistance to phenylamide fungicides: a case study with Phytophthora infestans involving mating type and race structure. Annual Rev. Phytopathol., 34(1): 549-572.

Gisi U, Sierotzki H. 2008. Fungicide modes of action and resistance in downy mildews. European J. Plant Pathol., 122(1): 157-167.

Goodwin SB, Smart CD, Sandrock RW, Deahl KL, Punja ZK, Fry WE. 1998. Genetic change within populations of Phytophthora infestans in the United States and Canada during 1994 to 1996: Role of migration and recombination. Phytopathol., 88(9): 939949.

Goodwin SB, Sujkowski LS, Fry WE. 1996. Widespread distribution and probable origin of resistance to metalaxyl in clonal genotypes of Phytophthora infestans in the United States and western Canada. Phytopathol., 86(7): 793-799.

Haverkort AJ, Boonekamp PM, Hutten R, Jacobsen E, Lotz L, Kessel G, Visser R, van der Vossen E. 2008. Societal costs of late blight in potato and prospects of durable resistance through cis-genic modification. Potato Res., 51(1): 47-57.

Inglis DA, Johnson DA, Legard DE, Fry WE, Hamm PB. 1996. Relative resistances of potato clones in response to new and old populations of Phytophthora infestans. Plant Disease, 80(5): 575-578.

Jmour W, Hamada W. 2006. First report of A2 mating type of Phytophthora infestans in Tunisia using molecular markers and some observations on its metalaxyl resistance. Tun. J. Plant Prot., 1: 85-92.

Jung G, Dicklow B, Jo Y, Chang S, Wick R. 2007. Chemical classes and modes of action for fungicides registered for use on turf grasses. University of Massachusetts-Amherst.

Kankwatsa P, Hakiza JJ, Olanya M, Kidenamariam HM, Adipala E. 2003. Efficacy of different fungicide spray schedules for control of potato late blight in Southwestern Uganda. Crop Prot., 22(3): 545-552.

Kato M, Mizubuti ES, Goodwin SB, Fry WE. 1997. Sensitivity to protectant fungicides and pathogenic fitness of clonal lineages of Phytophthora infestans in the United States. Phytopathol., 87:973-978.

Majeed A, Ahmad H, Ali M, Khan H. 2014b. Effect of systemic and contact fungicides on late blight disease and tuber yield of potato. J. Agric. Technol., 10(1): 209-17.

Majeed A, Ahmad H, Chaudhry Z, Jan G, Alam J, Muhammad Z. 2011. Assessment of leaf extracts of three medicinal plants against late blight of potato in Kaghan valley, Pakistan. J. Agric. Technol., 7(4): 1155-1161.

Majeed A, Chaudhry Z, Muhammad Z. 2014a. Changes in Foliar Glycoalkaloids Levels of Potato (Solanum tuberosum) Triggered by Late Blight Disease Severity. Int. J. Agric. Biol., 16(3): 609-613.

Majeed A, Chaudhry Z, Muhammad Z. 2014c. Variation in the Aggressiveness of Phytophthora infestans Pathotypes Collected from Different Potato Fields of Khyber Pakhtunkhwa (Pakistan). Int. J. Agric. Biol., 16(4), 807-812.
Majeed A, Chaudhry Z, Haq I, Muhammad Z, Rasheed H. 2015. Effect of aqueous leaf and bark extracts of Azadirachta indica A. Juss, Eucalyptus citriodora Hook and Pinus roxburghii Sarg. on late blight of potato. Pak. J. Phytopathol., 27(1): 13-18.

Mantecon JD. 2007. Potato yield increases due to fungicide treatment in Argentinian early blight (Alternaria solani) and late blight (Phytophthora infestans) field trials during the 1996-2005 seasons. Fung. Nemat. Tests., 55:221.

Miller JS, Johnson DA, Hamm PB. 1998. Aggressiveness of isolates of Phytophthora infestans from the Columbia Basin of Washington and Oregon. Phytopathol., 88(3): 190-197.

Mukalazi J, Adipala E, Sengooba T, Hakiza JJ, Olanya M, Kidanemariam HM. 2001. Metalaxyl resistance, mating type and pathogenicity of Phytophthora infestans in Uganda. Crop Prot., 20(5): 379-388.

Sajid ZA. 2012. Biochemical characterization of in vitro salt tolerant cell lines and regenerated plants of potato (Solanum tuberosum $\mathrm{L}$.). PhD Thesis University of the Punjab.

Saville A, Graham K, Grünwald NJ, Myers K, Fry WE, Ristaino JB. 2015. Fungicide sensitivity of US genotypes of Phytophthora infestans to six oomycete-targeted compounds. Plant Dis., 99(5): 659-666.

Schepers H. 1996. Rain fastness of fungicides used to control Phytophthora infestans. In 13th European Association of Potato Research Conference (pp. 374-375).

Schumann GL, D'Arcy CJ. 2000. Late blight of potato and tomato. The Plant Health Instructor. DOI: 10.1094/PHI-I-2000-0724-01

Schwinn FJ, Margot P. 1991. Agricultural Division, Ciba-Geigy AG, 4002 Basle, Switzerland. Phytophthora Infestans, the Cause of Late Blight of Potato, 7: 225.

Song J, Bradeen JM, Naess SK, Raasch JA, Wielgus SM, Haberlach GT, Helgeson JP. 2003. Gene RB cloned from Solanum bulbocastanum confers broad spectrum resistance to potato late blight. Proc. National Acad. Sci., 100(16): 9128-9133.

Vincelli P, Dixon E. 2002. Resistance to QoI (strobilurin-like) fungicides in isolates of Pyricularia grisea from perennial ryegrass. Plant Dis., 86(3): 235-240.

Whisson SC, Boevink PC, Wang S, Birch PR. 2016. The cell biology of late blight disease. Current Opinion in Microbiology, 34: 127-135.

Yuan SK, Liu XL, Si NG, Dong J, Gu BG, Jiang H. 2006. Sensitivity of Phytophthora infestans to flumorph: in vitro determination of baseline sensitivity and the risk of resistance. Plant Pathol., 55(2): 258-263.

Yuen JE, Andersson B. 2013. What is the evidence for sexual reproduction of Phytophthora infestans in Europe? Plant Pathol., 62(3): 485-491.

Zadoks JC. 2008. The potato murrain on the European continent and the revolutions of 1848. Potato Res 51:5-45 